\title{
Associations Between M235T Polymorphism in the AGT Gene and Cancer: An Updated Systematic Review and A Meta-analysis
}

Jun-Yan Kou

Hangzhou Cancer Hospital

Jing Huang ( $\sim$ huangjingdoc@tom.com )

Hangzhou Cancer Hospital https://orcid.org/0000-0003-2253-0507

Research

Keywords: Polymorphism, Cancer, Angiotensin, Meta-analysis

Posted Date: June 15th, 2021

DOl: https://doi.org/10.21203/rs.3.rs-592038/v1

License: (c) (i) This work is licensed under a Creative Commons Attribution 4.0 International License. Read Full License 


\section{Abstract}

Background: We assessed the relationship between AGT gene M235T polymorphism and the susceptibility to cancer by performing an updated meta-analysis.

Methods: This study retrospectively searched related articles in the electronic databases. Afterwards, we determined combined odds ratios (ORs) and related $95 \%$ confidence intervals (Cls) by the fixed- or random-effects model.

Results: The present meta-analysis enrolled altogether 9 articles. On the whole, the relationship between AGT M235T polymorphism and the cancer risk was not significant among the entire population(TT vs MM:OR=1.28,95\%Cl=0.80-2.04;TM vs MM: OR=0.90, 95\%Cl = 0.53-1.52; Recessive model: $\mathrm{OR}=1.13,95 \% \mathrm{Cl}=0.83-$ 1.52; Dominant model: $\mathrm{OR}=0.93,95 \% \mathrm{Cl}=0.55-1.57)$. But the relationship of $\mathrm{AGT} \mathrm{M} 235 \mathrm{~T}$ polymorphism with the digestive cancer risk was significant upon subgroup analysis stratified according to cancer type (TT vs MM:OR=1.68,95\%Cl=1.11-2.54;TM vs MM: OR=1.34, 95\%Cl = 0.97-1.85; Recessive model: OR=1.27, 95\%Cl = 0.951.70; Dominant model: $\mathrm{OR}=1.45,95 \% \mathrm{Cl}=1.07-1.96)$.

Conclusion: According to findings in the present meta-analysis, AGT M235T polymorphism may be possibly related to digestive cancer susceptibility.

\section{Introduction}

Cancer greatly affects the global economy and public health. According to statistics, 14 million cancer patients are diagnosed in 2012, and the cancer morbidity is predicted to increase to nearly 22 million in 2030[1]. At present, the cancer pathogenic mechanism remains largely unclear, and cancer is reported as a complicated condition induced by numerous factors, such as genetic factors, smoking, excessive drinking, chemical dyes, high calorific diet, or their combination[2]. Typically, genetic factors are recognized to exert vital parts in cancer risk, with numerous cancer pathogenesis-related genes being identified as the cancer risk genes[3].

Renin-angiotensin system (RAS) is the hormone signaling pathway, which has been suggested to modulate blood pressure (BP) and cardiovascular homeostasis. Besides, RAS within local tissues is possibly associated with cancer genesis and progression[4]. In brief, renin can release 10 amino acids (aa) in angiotensinogen (AGT) for forming Ang I as well as the great protein (des (Ang I) AGT). Both des (Ang I) AGT and AGT have been recognized as the non-inhibitory serpins inhibiting new blood vessel formation[5]. Then, ACE can eliminate the above 2 aa from Ang I for generating Ang II. Notably, Ang II represents a major RAS active peptide that can promote cell proliferation and new blood vessel formation via angiotensin II type 1 receptor (AGTR1)[6].

AGT gene is 12,068 bp in length and located on chromosome 1q42.2, and there are 4 introns and 5 exons in the gene coding region. Mutations in AGT gene mostly result from thymine nucleotide $(T)$ substitution by cytosine nucleotide (C) at the +704 position in exon 2. Therefore, the codon 235-encoded methionine (Met) is replaced by threonine (Thr) (also referred to as M235T), and 2 alleles are formed, including 235T (variant type) and 235M (wild type). Altogether 3 genotypes are detected among the population, which are homozygous 235TT and 235MM, as well as heterozygous 235M[7]. As discovered by Paillard and colleagues, AGT-235 T allele elevated the plasma AGT content[8], which induced smooth muscle proliferation and contraction of small arteries, lipid deposition and hypertrophy of vascular smooth muscle cells (VSMCs), increased norepinephrine production and excited the sympathetic nervous system. 
According to previous meta-analysis, the M235T variant in AGT gene is not related to the susceptibility to cancer[9]. But that meta-analysis only involves a small sample size and does not take into account some latest studies. The aim of the present study was to compile case-control research and updated meta-analyses to explore the association between AGT M235T polymorphism and susceptibility for cancer, so as to more accurately assess the cancer risk.

\section{Methods}

\section{Retrieval protocol}

This meta-analysis was carried out independently in line with guidelines of the preferred reporting items for systematic reviews and meta-analyses (PRISMA)[10]. Electronic databases, like PubMed, CNKI, Web of Science, Embase, Wanfang, and Cochrane library were searched for identifying articles that examined the association of AGT M235T polymorphism with cancer risk from inception to March 1st, 2021, using the keywords below, "Angiotensinogen", "M235T", "AGT", "polymorphism or mutation" and "cancer". At the same time, the reference lists in related studies were manually searched to avoid omitting any eligible study. No language restriction was applied in literature retrieval.

\section{Inclusion and Exclusion}

Eligible researches were enrolled according to the inclusion criteria:(1) studies that assessed the relationship of AGT M235T polymorphism with cancer risk, (2) case-control studies, (3) those with available genotyping information. The following was the exclusion criteria: (1) articles not related to cancer, (2) reviews, (3) articles with no available data, (4) duplicates.

\section{Data extraction}

Two investigators reviewed the related articles and collected data, and any disagreement between them was settled by the opinion of a third reviewer. The following information was collected, including first author, region, publication year, case and control numbers, case and control genotype frequencies, together with Hardy-Weinberg equilibrium (HWE) of control group.

\section{Quality assessment}

According to Table 1, the quality assessment rules were used for quality evaluation of the articles. ${ }^{11}$ In brief, study quality was evaluated based on control source, sample size, case representativeness, diagnosis of cancer, genotyping quality evaluation and HWE, and the overall score was between 0 and 15 . Studies that had a score $\geq$ 10 were deemed as high quality, while those that had a score $<10$ as "low quality". 
Table 1

Scale for quality assessment.

\begin{tabular}{|c|c|}
\hline Criteria & Score \\
\hline Source of cases & 3 \\
\hline Selected from population or cancer registry & 2 \\
\hline Selected from hospital & 1 \\
\hline $\begin{array}{l}\text { Selected from pathology archives, but without description } \\
\text { Not described }\end{array}$ & 0 \\
\hline Source of controls & 3 \\
\hline Population-based & 2 \\
\hline Blood donors or volunteers & 1 \\
\hline $\begin{array}{l}\text { Hospital-based (cancer-free patients) } 1 \\
\text { Not described } 0\end{array}$ & 0 \\
\hline Specimens of cases determining genotypes & 3 \\
\hline $\begin{array}{l}\text { White blood cells or normal tissues } \\
\text { Tumor tissues or exfoliated cells of tissue }\end{array}$ & 0 \\
\hline Hardy-Weinberg equilibrium in controls & 3 \\
\hline $\begin{array}{l}\text { Hardy-Weinberg equilibrium } \\
\text { Hardy-Weinberg disequilibrium }\end{array}$ & 0 \\
\hline Total sample size & 3 \\
\hline$\geq 1000$ & 2 \\
\hline$\geq 500$ but $<1000$ & 1 \\
\hline$\geq 200$ but $<500$ & 0 \\
\hline$>0$ but $<200$ & \\
\hline
\end{tabular}

\section{Statistical analysis}

- Meta-analysis was carried out by adopting STATA12.0. ORs together with related 95\% Cls were employed for evaluating correlation of AGT M235T polymorphism with cancer susceptibility under different comparisons, including heterozygote (TM vs MM), homozygote (TT vs MM), recessive model (TT vs MM + TM) and dominant model(TT + TM vs MM) between groups. Moreover, $\chi^{2}$ test was utilized for determining HWE regarding the distribution of genotype among all the enrolled researches. Heterogeneity was analyzed by $\mathrm{I}^{2}$ statistic, and $\mathrm{I}^{2}>50 \%$ suggested heterogeneity. Subgroup analyses according to cancer type, ethnicity and quality scores were also conducted. Afterwards, this study also conducted sensitivity analysis through eliminating a single study each time, showing suspect on one study of excessive sensitivity because the omission of this specific study yielded to the estimation beyond the $95 \% \mathrm{Cl}$ of the pooled analysis. Finally, we evaluated Begg's funnel plot for possible publication bias. 
Results

\section{Characteristics of Included Studies}

Altogether 699 related studies were searched; at last, nine of them were included int othe present meta-analysis according to the pre-determined study inclusion and exclusion criteria[12-20]. All our collected articles were published from 2007 to 2020 . Figure 1 shows the study screening flow chart. In brief, HWE test was carried out in the nine studies to examine the distribution of genotype in control group. As a result, all studies did not deviate from the HWE, with the exception of John et al and Pringle et al. All the enrolled studies had the quality score $>10$ points, with the exception of John et al, indicating that these studies had high study quality. With regard to cancer type, 3 studies were on digestive cancer and 3 were on breast cancer (BC) to examine AGT M235T polymorphism. Table 2 displays the study features and methodological quality.

Table 2

Characteristics of the included studies of AGT M235T polymorphism.

\begin{tabular}{|c|c|c|c|c|c|c|c|c|}
\hline $\begin{array}{l}\text { Study } \\
\text { included }\end{array}$ & Year & Cancer type & Race & $\begin{array}{l}\text { Cases/ } \\
\text { Controls }\end{array}$ & $\begin{array}{l}\text { Genotypes } \\
\text { for cases }\end{array}$ & $\begin{array}{l}\text { Genotypes } \\
\text { for } \\
\text { controls }\end{array}$ & $\begin{array}{l}\text { HWE } \\
\text { test }\end{array}$ & $\begin{array}{l}\text { Quality } \\
\text { scores }\end{array}$ \\
\hline & & & & & $\begin{array}{l}\text { TT TM } \\
\text { MM }\end{array}$ & $\begin{array}{l}\text { TT TM } \\
\text { MM }\end{array}$ & & \\
\hline $\begin{array}{l}\text { González- } \\
\text { Zuloeta }\end{array}$ & 2007 & $\begin{array}{l}\text { Breast } \\
\text { cancer }\end{array}$ & Caucasian & $962 / 760$ & $\begin{array}{l}244492 \\
226\end{array}$ & $\begin{array}{l}225354 \\
181\end{array}$ & 0.07 & 12 \\
\hline Vairaktaris & 2008 & Oral cancer & Caucasian & $163 / 124$ & 238753 & 156148 & 0.51 & 10 \\
\hline Vasku & 2009 & $\begin{array}{l}\text { Colorectal } \\
\text { cancer }\end{array}$ & Caucasian & $102 / 101$ & 5010050 & 319673 & 0.95 & 10 \\
\hline Shibata & 2011 & $\begin{array}{l}\text { Gastric } \\
\text { cancer }\end{array}$ & Asian & $206 / 210$ & 140579 & 142608 & 0.60 & 10 \\
\hline $\begin{array}{l}\text { Mendizábal- } \\
\text { Ruiz }\end{array}$ & 2011 & $\begin{array}{l}\text { Breast } \\
\text { cancer }\end{array}$ & Mixed & $50 / 224$ & 211712 & 7511831 & 0.15 & 10 \\
\hline Fishchuk & 2013 & $\begin{array}{l}\text { Breast } \\
\text { cancer }\end{array}$ & Caucasian & $131 / 102$ & 296636 & 155532 & 0.27 & 10 \\
\hline Pringle & 2016 & $\begin{array}{l}\text { Endometrial } \\
\text { cancer }\end{array}$ & Caucasian & $183 / 133$ & 788322 & 405439 & 0.03 & 7 \\
\hline Wang & 2016 & Mixed & Asian & $104 / 1178$ & 62402 & $\begin{array}{l}838315 \\
25\end{array}$ & 0.47 & 12 \\
\hline John & 2019 & $\begin{array}{l}\text { Basal Cell } \\
\text { Carcinoma }\end{array}$ & Caucasian & 91/99 & 02071 & 46728 & 0.00 & 6 \\
\hline
\end{tabular}

\section{Meta-analysis results}

Table 3 lists the major findings from this meta-analysis and the heterogeneity. On the whole, AGT M235T polymorphism did not show significant relationship with cancer under each genetic model (TT vs MM:OR = $1.28,95 \% \mathrm{Cl}=0.80-2.04 ; \mathrm{TM}$ vs $\mathrm{MM}: \mathrm{OR}=0.90,95 \% \mathrm{Cl}=0.53-1.52$; Recessive model: $\mathrm{OR}=1.13,95 \% \mathrm{Cl}=0.83-1.52$; Dominant model: $\mathrm{OR}=0.93,95 \% \mathrm{Cl}=0.55-1.57)$. 
Table 3

Summary ORs and $95 \% \mathrm{Cl}$ of AGT M235T polymorphism with cancer risk.

\begin{tabular}{|c|c|c|c|c|c|}
\hline Variables & $\begin{array}{l}\mathrm{N} \\
\mathrm{a}\end{array}$ & TT vs MM & TM vs MM & Dominant model & Recessive model \\
\hline & & OR(95\%Cl) Model & OR(95\%Cl) Model & OR(95\%Cl) Model & OR(95\%Cl) Model \\
\hline Total & 9 & $1.28(0.80-2.04) R$ & $0.90(0.53-1.52) R$ & $0.93(0.55-1.57) R$ & $\begin{array}{l}1.13(0.83-1.52) \\
R\end{array}$ \\
\hline \multicolumn{6}{|l|}{ Race } \\
\hline Asian & 2 & $0.89(0.40-2.01) \mathrm{F}$ & $1.06(0.47-2.39) \mathrm{F}$ & $0.94(0.42-2.08) \mathrm{F}$ & $\begin{array}{l}0.78(0.46-1.31) \\
\mathrm{R}\end{array}$ \\
\hline Caucasian & 6 & $1.50(0.81-2.80) R$ & $0.97(0.52-1.83) \mathrm{R}$ & $1.01(0.53-1.93) R$ & $\begin{array}{l}1.27(0.83-1.97) \\
R\end{array}$ \\
\hline \multicolumn{6}{|l|}{ Cancer type } \\
\hline Breast cancer & 3 & $0.91(0.72-1.16) \mathrm{F}$ & $0.86(0.50-1.47) \mathrm{R}$ & $0.94(0.65-1.36) \mathrm{F}$ & $\begin{array}{l}1.14(0.69-1.89) \\
R\end{array}$ \\
\hline $\begin{array}{l}\text { Digestive } \\
\text { cancer }\end{array}$ & 3 & $1.68(1.11-2.54) \mathrm{F}$ & $1.34(0.97-1.85) \mathrm{F}$ & 1.45(1.07-1.96) F & $\begin{array}{l}1.27(0.95-1.70) \\
F\end{array}$ \\
\hline \multicolumn{6}{|l|}{ Quality } \\
\hline high & 7 & $1.19(0.82-1.74) \mathrm{R}$ & $1.13(0.95-1.35) \mathrm{F}$ & $1.11(0.94-1.32) \mathrm{F}$ & $\begin{array}{l}1.08(0.80-1.45) \\
R\end{array}$ \\
\hline low & 2 & $\begin{array}{l}0.49(0.01-41.59) \\
\mathrm{R}\end{array}$ & $\begin{array}{l}0.57(0.03-12.34) \\
\mathrm{R}\end{array}$ & $\begin{array}{l}0.58(0.02-14.93) \\
\mathrm{R}\end{array}$ & $\begin{array}{l}0.66(0.05-8.64) \\
R\end{array}$ \\
\hline
\end{tabular}

As revealed by subgroup analysis stratified by ethnicity, AGT M235T polymorphism did not show significant relationship with cancer susceptibility in the Caucasian or the Asian population. Meanwhile, subgroup analysis stratified by quality score suggested that AGT M235T polymorphism did not show significant relationship with cancer susceptibility. According to subgroup analysis based on cancer type, significant association was found in digestive cancer (Fig. 2,GG vs AA: $\mathrm{OR}=2.38,95 \% \mathrm{Cl}=1.24-4.55$; $\mathrm{GA}$ vs $\mathrm{AA}: \mathrm{OR}=1.34,95 \% \mathrm{Cl}=0.82-2.20$; recessive model: $\mathrm{OR}=2.17,95 \% \mathrm{Cl}=1.54-3.0$; dominant model: $\mathrm{OR}=1.59,95 \% \mathrm{Cl}=1.06-2.39$ ), rather than breast cancer.

\section{Sensitivity Analysis}

- When each individual study was eliminated, the pooled results were not changed, which indicated statistical significance of our results(Fig. 3).

\section{Publication bias}

We drew the Begg's funnel plot for assessing the possible publication bias among the enrolled articles. No evident asymmetry was observed in the funnel plot(Fig. 4). 


\section{Discussion}

At present, cancer is recognized to be a major cause leading to mortality in the world. It has brought severe social and economic burdens on the health-care system across diverse countries; what's worse, it has deteriorated the patient life quality[21]. Regardless of the progresses made in cancer treatment, cancer prognosis is still poor. Cancer represents a kind of multifactorial disorder. As reported in some studies, the interaction between polymorphisms and environmental factors exerts a vital part in cancer genesis. More and more studies find that RAS affects cell proliferation, inflammation, apoptosis and tissue angiogenesis. However, most existing casecontrol studies are conducted to examine the relationship of AGT M235T polymorphism with the susceptibility to cancer. Nonetheless, no consistent results are obtained. This meta-analysis was carried out for assessing the relationship of AGT M235T polymorphism with the susceptibility to cancer.

Our findings suggest that this polymorphism was not related to a higher susceptibility to cancer. As revealed by subgroup analysis stratified by race, AGT M235T polymorphism was significantly associated with cancer risk among the Asian and Caucasian populations. When stratified by cancer type, AGT M235T polymorphism was significantly associated with digestive cancer risk, but not the breast cancer.Discrepancies between study could possibly due to a different role of this polymorphism in different cell types or tissues. It remains unknown about the mechanism regarding the connection of AGT M235T polymorphism with digestive cancer risk. Firstly, AGT M235T polymorphism is linked with AGT content in plasma. AGT participates in cardiovascular remodeling, vascular tone, water and salt homeostasis, while high salt consumption represents one of the risk factors for digestive cancer. ${ }^{17}$ Secondly, AGT A-20C polymorphism is reported previously to predict a higher susceptibility to gastric cancer. There is a linkage disequilibrium of A-20C with M235T polymorphism sites of AGT gene. These two polymorphisms may be cooperate with each other to add the risk of disease[22].

Certain limitations must be noted in the present meta-analysis. Firstly, raw data from the enrolled articles were lacking, which restricted our ability to better evaluate the associations between genes and between genes and the environment. Secondly, each of the enrolled articles was of retrospective nature, which might inevitably lead to subject selection bias, finally impacting our result reliability. Thirdly, the present meta-analysis just enrolled the published articles, while the related unpublished articles were not enrolled, which might cause a potential publication bias.

To sum up, our meta-analysis reveals that AGT M235T polymorphism is related to susceptibility to digestive cancer. More large-scaled case-control studies should be conducted to explore the potential relationships between genes and between genes and the environment with cancer incidence.

\section{Declarations}

\section{Conclusions section}

According to findings in the present meta-analysis, AGT M235T polymorphism may be possibly related to digestive cancer susceptibility.Relevance of the study reported:Jianjun Lin, Jiayu Chen, Chibo Liu.AGT M235T variant is not associated with risk of cancer. J Renin Angiotensin Aldosterone Syst. 2015;16:448-52.

\section{Acknowledgements}

Not applicable. 


\section{Authors' contributions}

Jun-Yan Kou designed the study and drafted the manuscript. Jun-Yan Kou was responsible for the collection and analysis of the experimental data. Jing Huang revised the manuscript critically for important intellectual content. The authors read and approved the final manuscript.

\section{Funding}

Not applicable.

\section{Availability of data and materials}

The datasets used and/or analyzed during the current study are available from the corresponding author on reasonable request.

\section{Declarations}

\section{Ethics approval and consent to participate}

The study was approved by the Ethics Committee of Hangzhou Cancer Hospital.

\section{Consent for publication}

Not applicable.

\section{Competing interests}

The authors declare that they have no competing interests

\section{References}

1. Raju K, Mandal N, Akhter S, Haque AK, Panda RD, Mittal. Mohammed A A Alqumber. No correlation between TIMP2 -418 G > C polymorphism and increased risk of cancer: Evidence from a meta-analysis. PLoS One. 2014;9(8):e88184.

2. Mohammed AA, Alqumber N, Akhter S, Haque, Aditya K, Panda, Raju K, Mandal. Evaluating the association between p53 codon $72 \mathrm{Arg}>$ pro polymorphism and risk of ovary cancer: A meta-analysis. PLoS One. 2014;18(4):e94874.. ;;9.

3. Jing Jia J, Ren D, Xiao YL. Ruifen Sun. Association between the XRCC6 polymorphisms and cancer risks: A systematic review and meta-analysis. Med (Baltim). 2015;94:e283.

4. Takayasu Suganuma K, Ino K, Shibata H, Kajiyama T, Nagasaka S, Mizutani. et al. Functional expression of the angiotensin II type 1 receptor in human ovarian carcinoma cells and its blockade therapy resulting in suppression of tumor invasion, angiogenesis, and peritoneal dissemination. Clin Cancer Res. 2005;11:268694.

5. Jérôme Célérier A, Cruz N, Lamandé J-M, Gasc. Pierre Corvol. Angiotensinogen and its cleaved derivatives inhibit angiogenesis. Hypertension. 2002,39:224-8.

6. Naoko Koyama Y, Nishida T, Ishii T, Yoshida Y, Furukawa, Hisashi Narahara. Telmisartan induces growth inhibition, DNA double-strand breaks and apoptosis in human endometrial cancer cells. PLoS One. 
2014;9:e93050.

7. ElAlfy MS. Fatma Soliman Elsayed Ebeid, Tarek Mostafa Kamal, Deena Samir Eissa, Eman Abdel Rahman Ismail, Samar Hassan Mohamed. Angiotensinogen M235T gene polymorphism is a genetic determinant of cerebrovascular and cardiopulmonary morbidity in adolescents with sickle cell disease. J Stroke Cerebrovasc Dis. 2019;28:441-9.

8. Paillard F, Chansel D, Brand E, Benetos A, Thomas F, Czekalski S. et al. Genotype-phenotype relationships for the renin-angiotensin-aldosterone system in a normal population. Hypertension. 1999;34:423-9.

9. Jianjun Lin J, Chen, Chibo Liu.AGT M235T variant is not associated with risk of cancer. J Renin Angiotensin Aldosterone Syst. 2015;16:448 - 52.

10. Moher D, Liberati A, Tetzlaff J, Douglas G, Altman, PRISMA Group.Altman. Preferred reporting items for systematic reviews and metaanalyses:the PRISMA statement. PLoS Med. 2009;6:e1000097.

11. Jiang D-K, Ren W-H, Yao L, Wang W-Z, Peng B. Long Yu.Meta-analysis of association between TP53 Arg72Pro polymorphism and bladder cancer risk. Urology. 2012;76:765.e1-7.

12. Fishchuk LE. N G Gorovenko.Genetic polymorphisms of the renin-angiotensin system in breast cancer patients. Exp Oncol. 2013;35:101-4.

13. Stefanie Huhn M, Bevier A, Rudolph B, Pardini A, Naccarati. Rebecca Hein,et al.Shared ancestral susceptibility to colorectal cancer and other nutrition related diseases.BMC Med Genet. 2012;13:94.

14. Papaggelopoulos J, Angelopoulou A, Avgoustidis D, Koronellos N, Derka S, Vassiliou S, Yapijakis C,et al.Association of Polymorphisms in the Genes of Angiotensinogen and Angiotensin Receptors With Risk for Basal Cell Carcinoma. Anticancer Res. 2019;39:5525-30.

15. Adriana P, Mendizábal-Ruiz J, Morales XC, Martinez, Susan AG, Rubio. Laura Valdez, José G VásquezCamacho,et al.RAS polymorphisms in cancerous and benign breast tissue, J Renin Angiotensin Aldosterone Syst. 2011;12:85-92.

16. Pringle KG, Delforce SJ, Wang Y, Ashton KA, Proietto A, Otton G,et al.Geoffrey.Renin-angiotensin system gene polymorphisms and endometrial cancer. Endocr Connect. 2016;5:128 - 35.

17. Tomoyuki Shibata T, Tahara T, Arisawa. Ichiro Hirata.Polymorphism of the salt sensitivity gene angiotensinogen and gastric cancer risk. Mol Med Rep. 2011;4:723-6.

18. Eleftherios Vairaktaris C, Yapijakis A, Vylliotis S, Derka S, Vassiliou E, Nkenke,et al.Angiotensinogen polymorphism is associated with risk for malignancy but not for oral cancer. Anticancer Res. 2008;28:1675-9.

19. Anna, Vasků. Jirí Vokurka, Julie Bienertová-Vasků.Obesity-related genes variability in Czech patients with sporadic colorectal cancer: preliminary results. Int J Colorectal Dis. 2009;24:289 - 94.

20. Wang Y, Chen AX. CE Chen.Association of the renin-angiotensin system polymorphisms with incident cancer in chinese patients with type 2 diabetes. Labeled Immunoassays \& Clin Med. 2016;23:845 - 51.

21. Ward E, DeSantis C, Robbins A, Kohler B, Jemal A. Childhood and adolescent cancer statistics,2014. CA Cancer J Clin. 2014;64(2):83-103.

22. Mitsushige Sugimoto T, Furuta N, Shirai C, Kodaira M, Nishino M, Ikuma,et al. Role of angiotensinogen gene polymorphism on Helicobacter pylori infection-related gastric cancer risk in Japanese. Carcinogenesis. 2007 28:2036-40.

\section{Figures}



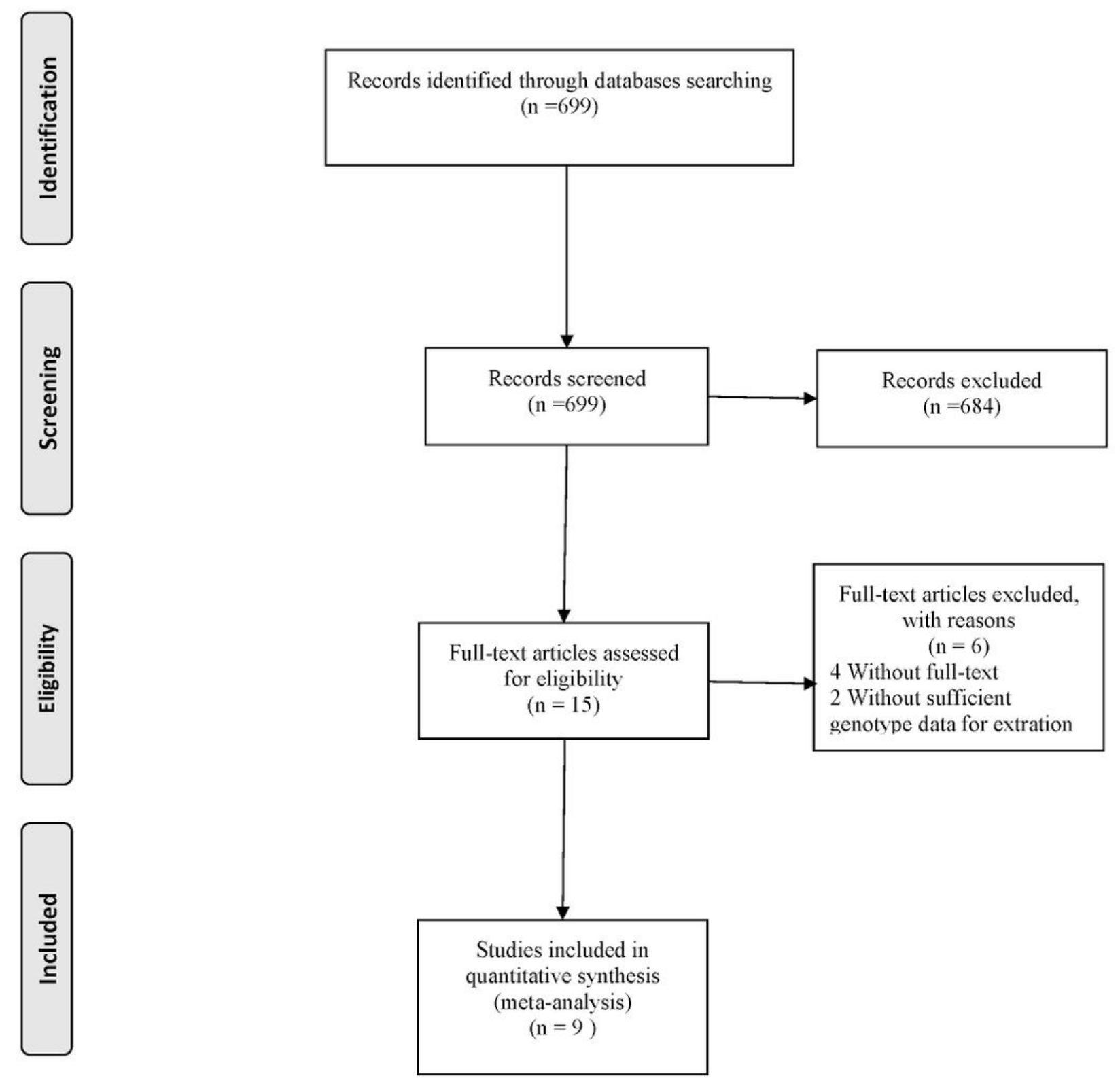

Figure 1

The flow diagram of included/excluded studies. 


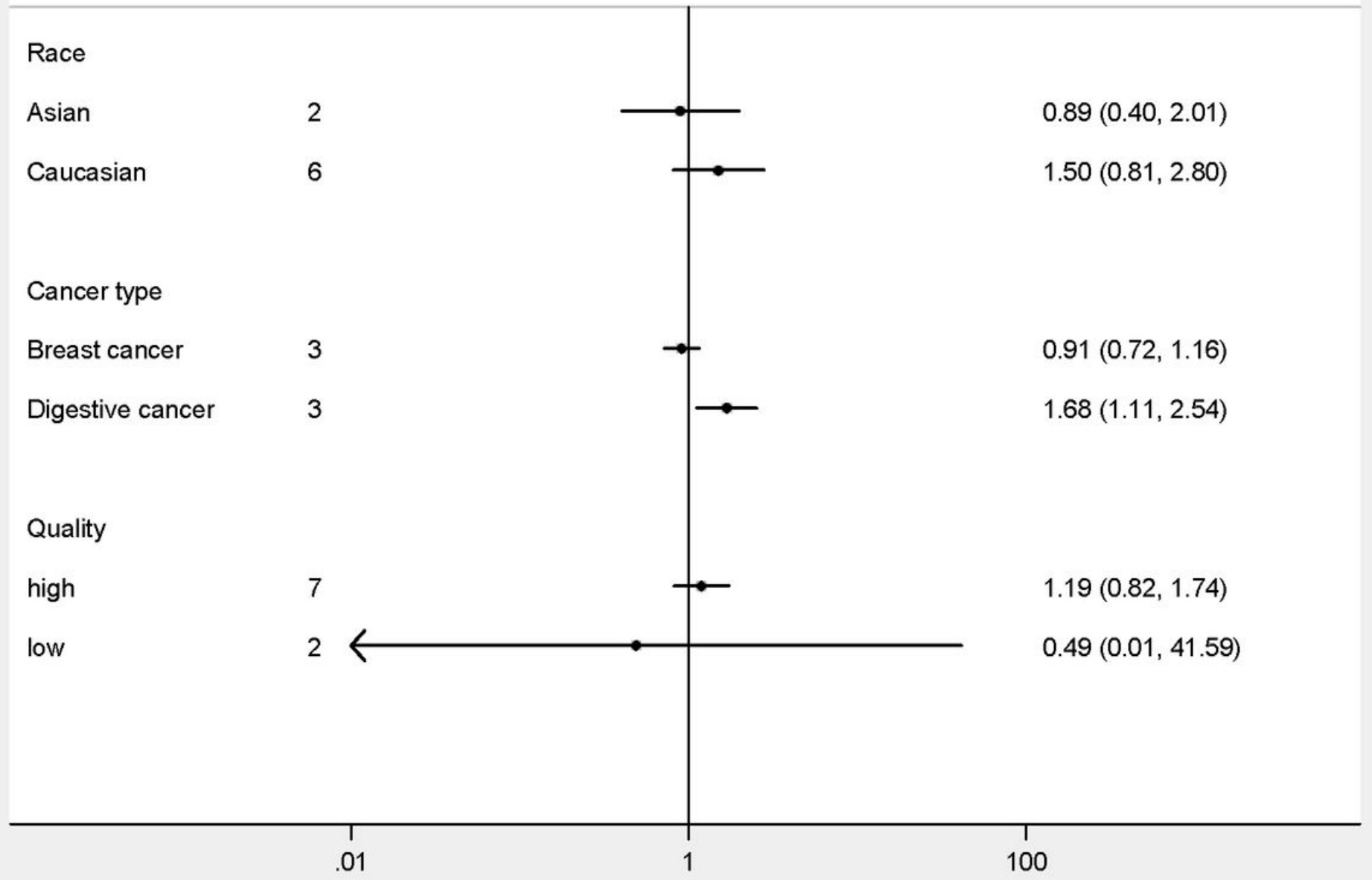

\section{Figure 2}

Forest plot for meta-analysis of the association between the M235T polymorphism and cancer risk with TT vs MM. 


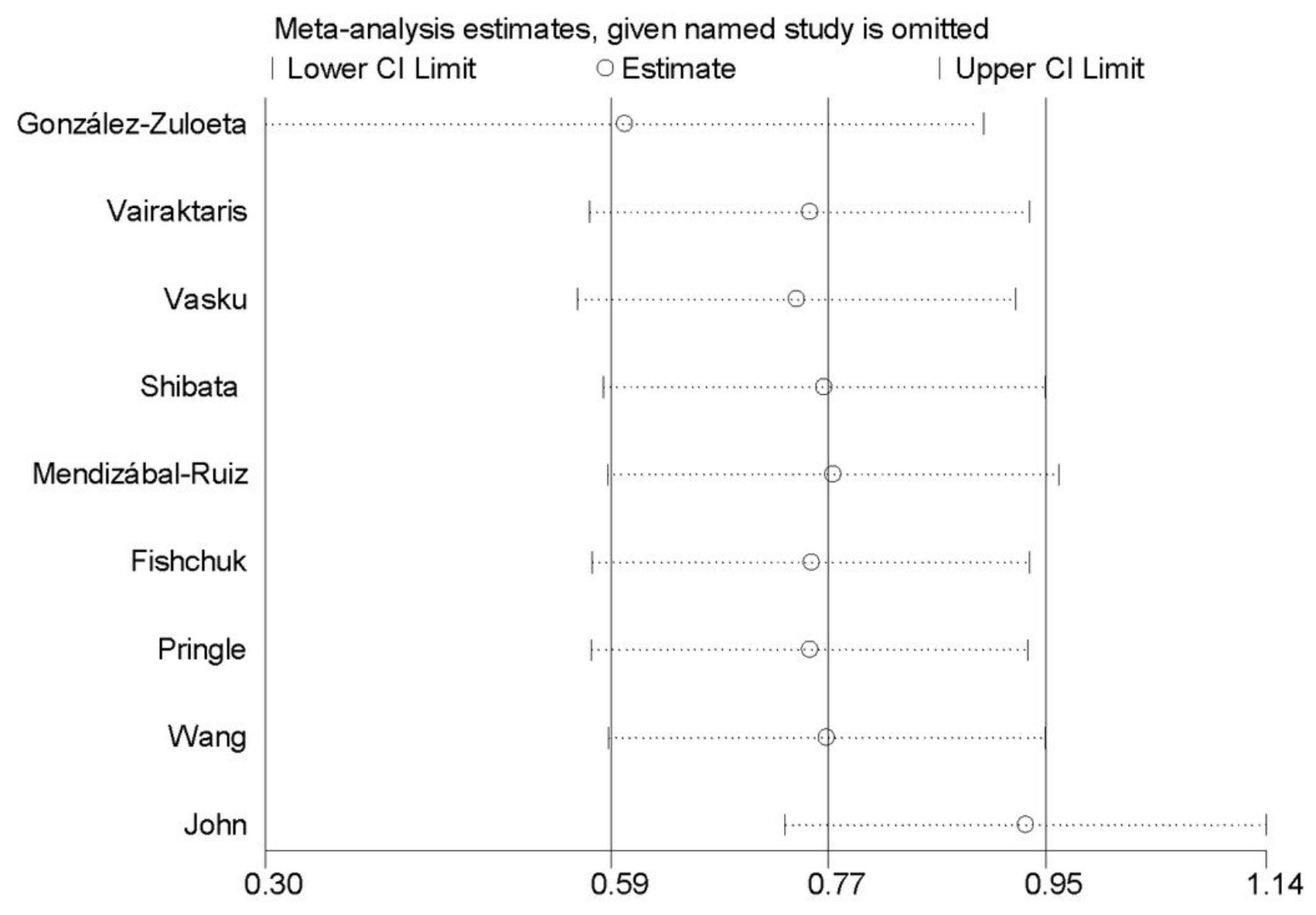

Figure 3

Sensitivity analysis of the association between the M235T polymorphism and cancer risk. 
Begg's funnel plot with pseudo 95\% confidence limits

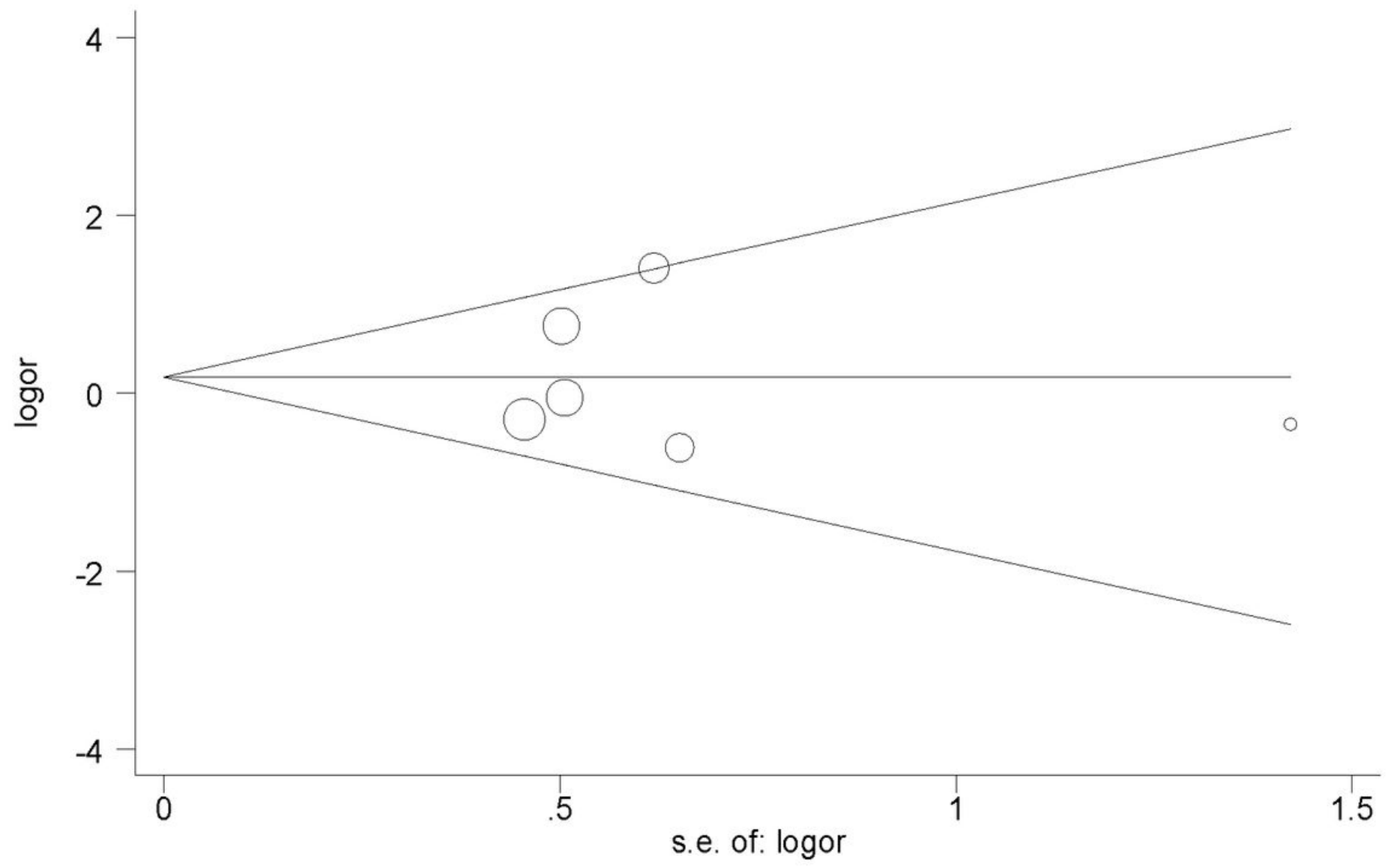

Figure 4

Begg's funnel plot analysis to detect potential publication bias for M235T polymorphism. 